\title{
Does the Progestogen Used in Combined Hormonal Contraception Affect Venous Thrombosis Risk?
}

Leo Han, MD*, Jeffrey $T$. Jensen, MD, MPH

\section{KEYWORDS}

- Progestin • Progestogen • Venous thromboembolism • Oral contraceptive

- Drospirenone

\section{KEY POINTS}

- All combined oral contraceptive pills carry a small, but increased risk for venous thromboembolism (VTE).

- Existing studies rely on observational data to estimate the risk for VTE of different progestogen subtypes.

- These studies vary in their ability to account for preexisting risk factors, confounders, and cohort-related effects.

- Despite heterogeneity in study results regarding the safety of different progestogens, the risk of VTE overall with combined oral contraceptives remains very low compared with pregnancy.

- The decision to prescribe a pill should be based on the unique risk factors and medical history of the individual woman.

\section{INTRODUCTION}

Almost 60 years after the pill first became available for contraception, more than a quarter of US women choose combined hormonal contraception $(\mathrm{CHC})$ for birth control. ${ }^{1}$ Over the years, the pill has undergone substantial modifications in chemistry, formulations, and dosing regimens, and transdermal patches and vaginal rings have been introduced. As a result, there is now a variety of combined hormonal methods to choose from. These different formulations contain both objectively demonstrated

Disclosure: See last page of the article.

Department of Obstetrics and Gynecology, Oregon Health \& Science University, 3181 Southwest

Sam Jackson Park Road, Portland, OR 97239, USA

* Corresponding author. Department of Obstetrics and Gynecology, Oregon Health \& Science

University, 3181 Southwest Sam Jackson Park Road, Mailcode: L466, Portland, OR 97239.

E-mail address: hanl@ohsu.edu

Obstet Gynecol Clin N Am - (2015) घ- -

http://dx.doi.org/10.1016/j.ogc.2015.07.007

0889-8545/15/\$ - see front matter (c) 2015 Published by Elsevier Inc. 
options, the basic formula for $\mathrm{CHC}$ remains the same: an estrogen coupled with a synthetic progestogen. Consequently, the most important risk of $\mathrm{CHC}$ has also remained the same: venous thromboembolism (VTE).

VTE is a life-threatening condition. Two-thirds manifest as deep vein thrombosis (DVT), whereas another third present as pulmonary embolism (PE). Mortality and morbidity for these conditions are serious. ${ }^{2}$ Studies estimate that $20 \%$ to $25 \%$ of all PE cases present as sudden death. ${ }^{3}$ Moreover, recurrent thromboembolism, chronic venous insufficiency, and pulmonary hypertension are important nonfatal sequelae of these diseases. ${ }^{4}$ Even in the most benign scenarios of simple, detected VTE, treatment requires a course of anticoagulation therapy that affects patient quality of life and confers risk from adverse bleeding scenarios. ${ }^{5}$

VTE was recognized almost immediately as a serious risk of combined oral contraceptive (COC) use. Once estrogen was identified as the culpable hormone, pharmaceutical companies scaled back the estrogen dose from what now seems like a massive load of $150 \mu \mathrm{g}$ of mestranol per pill to modern levels of 10 to $35 \mu \mathrm{g}$ of ethinyl estradiol (EE). As predicted, reducing estrogen doses decreased VTE risks without sacrificing efficacy. Clinicians now accept that the risk of VTE is about 2-fold higher in COC users on a background rate of about 5 to 10 per 10,000 woman-years in healthy nonpregnant women. ${ }^{6}$ CHCs also increase the risk of arterial thromboembolism (ATE). ${ }^{7}$ Although ATE events such as myocardial infarction (MI) and stroke are extremely rare in reproductive-aged women, the consequences are severe. However, in healthy, nonsmoking women, less than 35 years old, using low-dose (eg, $<50 \mu \mathrm{g}$ of EE) pills, the increase in risk is negligible. ${ }^{8,9}$ Furthermore, although age, smoking, hypertension, and to a lesser extent migraine headache with aura have been reported to modify the risk of ATE $^{8}$ associated with $\mathrm{CHC}$ use, the type of progestogen in a formulation has not been implicated as an additional risk factor. ${ }^{7}$ In contrast, considerable scientific debate continues regarding whether the type of progestogen used in a combined method modifies VTE risk. ${ }^{10}$

Because all but the most recently introduced COCs use the same synthetic estrogen, EE, the progestogen used differentiates most formulations. New progestogens were developed to address side effects related to androgenic properties of the 19-nortestosterone derivative progestogens norethindrone and levonorgestrel (LNG). This steady evolution of less androgenic progestogens led to grouping formulations into generations so that pills of similar characteristics could be discussed together. Although this classification system does not provide a true representation of structural chemistry, a body of literature had adopted the convention. However, regulatory approval of these new formulations as contraceptives did not require proof of additional health benefit or tolerability compared with existing low-dose formulations. Therefore, controversy developed because these newer progestogens were linked to an increased risk of VTE in some epidemiologic studies. ${ }^{11-15}$

For more than 2 decades, this controversy has persisted. Because VTE is an uncommon to rare event, phase 3 premarketing studies are underpowered to evaluate these outcomes, and are typically not conducted using an active comparator. Although case-control and database studies can provide useful insights on rare events, inherent limitations of these designs prevent ascertainment of key confounders. ${ }^{10}$ This article examines the complex problems that obscure this debate, and highlight the merits and shortcomings of the most important and recent research contributions.

\section{TYPES OF PROGESTOGENS}

In addition to androgenicity, progestogens differ in several significant ways, including bioavailability, potency, and metabolism. ${ }^{16}$ Individual variation in metabolism may 
magnify these differences, explaining why the same progestogen may have different side effects in different users.

Table 1 categorizes progestins into their respective generations. The use of the term generation is misleading, because the assignment is based not only on the derivative molecules but also on the chronologic release of the drug to market. An alternative classification system grounded in structural and biological function has been detailed by Stanczyk and colleagues. ${ }^{17}$ This system groups progestogens according to their steroid scaffold relationship to progesterone or testosterone, and further subdivides compounds based on key substitutions to the base molecule (Fig. 1; see Table 1). ${ }^{17}$ Progestogens structurally related to progesterone are classified as pregnanes or 19-norpregnanes based on the presence or absence of a methyl group at carbon (C)-10, and subdivided based on acetylation at C-17. Medroxyprogesterone acetate is an example of a progesterone derivative used in contraception.

The most commonly used contraceptive progestogens are derivatives of testosterone; removal of the C-19 methyl group yields the 19-nortestosterone scaffold used by all of these compounds except drospirenone (DRSP). Testosterone-derived progestogens can be further divided into those that are ethinylated (ethinyl group at

\begin{tabular}{|c|c|c|c|c|}
\hline $\begin{array}{l}\text { Progestin } \\
\text { Generation }\end{array}$ & Parent Structure & $\begin{array}{l}\text { Metabolite } \\
\text { Family } \\
\end{array}$ & Progestogens & Common Products \\
\hline First & $\begin{array}{l}\text { Testosterone } \\
\text { (ethinylated } \\
\text { at carbon 17) }\end{array}$ & Estrane & $\begin{array}{l}\text { Norethynodrel, } \\
\text { norethindrone, } \\
\text { norethindrone } \\
\text { acetate, ethynodiol } \\
\text { diacetate }\end{array}$ & $\begin{array}{l}\text { Loestrin, } \\
\text { Ortho-Novum }\end{array}$ \\
\hline \multirow[t]{2}{*}{$\begin{array}{l}\text { Not } \\
\text { classified }\end{array}$} & $\begin{array}{l}\text { Progesterone } \\
\text { (methylated } \\
\text { at carbon 10) }\end{array}$ & Pregnane & $\begin{array}{l}\text { Medroxyprogesterone } \\
\text { acetate } \\
\text { Megestrol acetate }\end{array}$ & $\begin{array}{l}\text { Depo-Provera, } \\
\text { Megace }\end{array}$ \\
\hline & $\begin{array}{l}\text { Progesterone } \\
\text { (no methyl } \\
\text { group at } \\
\text { carbon 10) } \\
\end{array}$ & Norpregnane & $\begin{array}{l}\text { Nomegestrol acetate } \\
\text { Nesterone }\end{array}$ & Zoely ${ }^{a}$ \\
\hline Second & $\begin{array}{l}\text { Testosterone } \\
\text { (ethinylated } \\
\text { at carbon 13) } \\
\end{array}$ & Gonane & Norgestrel, LNG & $\begin{array}{l}\text { Mirena IUS, } \\
\text { Lo-Ovral, Alesse, } \\
\text { Seasonale } \\
\end{array}$ \\
\hline Third & $\begin{array}{l}\text { Testosterone } \\
\text { (ethinylated } \\
\text { at carbon 13) }\end{array}$ & Gonane & $\begin{array}{l}\text { Desogestrel, } \\
\text { norgestimate, } \\
\text { gestodene, } \\
\text { etonogestrel }\end{array}$ & $\begin{array}{l}\text { Ortho-Cyclen, } \\
\text { Mircette, } \\
\text { Femodene, } \\
\text { Nexplanon, } \\
\text { NuvaRing } \\
\end{array}$ \\
\hline Fourth & $\begin{array}{l}\text { Testosterone } \\
\text { (no ethinyl } \\
\text { group at } \\
\text { carbon 17) }\end{array}$ & $\begin{array}{l}\text { Nonethinylated } \\
\text { estrane }\end{array}$ & $\begin{array}{l}\text { Drospirenone, } \\
\text { dienogest }\end{array}$ & $\begin{array}{l}\text { Yasmine, Yaz, } \\
\quad \text { Jeanine } \\
\text { Natazia } \\
\text { Qlaira }\end{array}$ \\
\hline
\end{tabular}

Abbreviation: IUS, intrauterine system.

${ }^{a}$ Not available in the United States.

Data from Stanczyk FZ, Hapgood JP, Winer S, et al. Progestogens used in postmenopausal hormone therapy: differences in their pharmacological properties, intracellular actions, and clinical effects. Endocr Rev 2013;34(2):171-208; and Hatcher RA, Trussell J, Nelson AL. Contraceptive Technology. Ardent Media; 2008. 
151

152

153

154

155

156

157

158

159

160

161

162

163

164

165

166

167

168

169

170

171

172

173

174

175

176

177

178

179

180

181

182

183

184

185

186

187

188

189

190

191

192

193

194

195

196

197

198

199

200

201

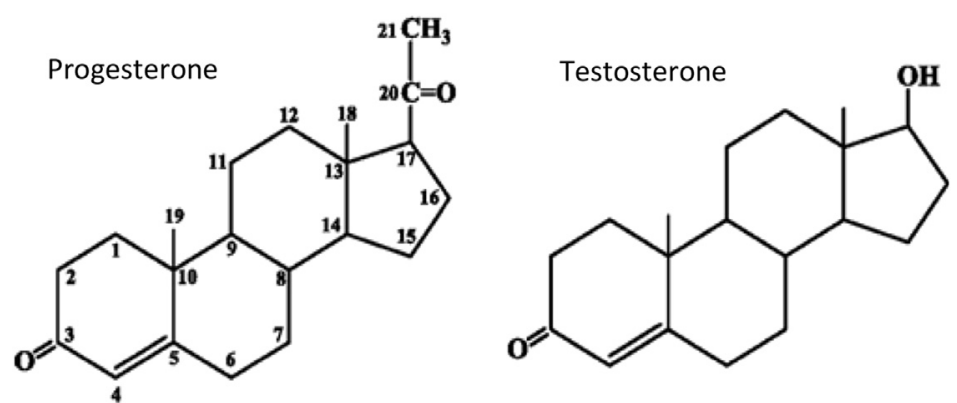

Fig. 1. Chemical structures of progesterone and testosterone with carbon numbering conventions.

C-17) or nonethinylated. The ethinylated groups include the norethindrone family of estranes as well as the LNG family of gonanes. Addition of an ethyl group at C-13 differentiates the gonanes from estranes. In the nonethinylated family, DRSP and dienogest are the most important molecules. DRSP is derived from an androstane scaffold and structurally related to spironolactone with a carbolactone group at C-17; this yields both antimineralocorticoid and antiandrogenic properties. Dienogest, a 19-nortestosterone derivative, has a cyano group at C-17 and also possesses antiandrogenic properties. Although this categorization system makes good scientific sense, VTE epidemiologic studies heavily favor the use of the traditional generation designations.

Because of long-standing and widespread use, LNG or second-generation progestogens have emerged as the reference group for most epidemiologic studies of $\mathrm{CHC}$ safety. LNG has been widely used in CHC since the 1980 s and is also found in several progestogen-only contraceptives including the LNG intrauterine system, contraceptive implants, and the LNG emergency birth control pill. Given its long, wellcharacterized history of safety and efficacy, studies usually report measures of association of newer methods relative to the VTE rates of pills containing LNG.

\section{PHYSIOLOGY OF COMBINED ORAL CONTRACEPTIVE USE AND VENOUS THROMBOEMBOLISM}

The increased risk of VTE arises from the changes that occur in the coagulation cascade brought on by estrogen. This estrogen effect represents an evolutionary adaptation of female mammals to the risk of hemorrhage that occurs with pregnancy. Estrogen leads to an increase in levels of thrombogenic clotting factors (factor I II, VII, $\mathrm{VIII}, \mathrm{X}$ ) as well as a decrease in levels of clotting inhibitors (tissue plasminogen activator, antiplasmin, protein S) (Fig. 2) that shifts the balance to favor clot formation. Several studies have shown that the type of progestogen used in a $\mathrm{CHC}$ influences the magnitude of the estrogen-induced changes in these various hemostatic biomarkers. ${ }^{18-20}$ Although the biological mechanism of this progestogen effect has not been elucidated, it seems to be through modification of the estrogen response rather than a direct effect, because progestogen-only contraception does not increase VTE risk. ${ }^{21}$ Complex interactions between estrogen, progestogen, and androgen signaling influence liver metabolism. Estrogens activate hepatic globulin synthesis. The high levels of estrogens seen by the liver following oral dosing are supraphysiologic. Although estradiol is converted to less potent estriol and estrone following the first pass, synthetic EE is more potent and also activates the liver during recirculation of 
202

203

204

205

206

207

208

209

210

211

212

213

214

215

216

217

218

219

220

221

222

223

224

225

226

227

228

229

230

231

232

233

234

235

236

237

238

239

240

241

242

243

244

245

246

247

248

249

250

251

252

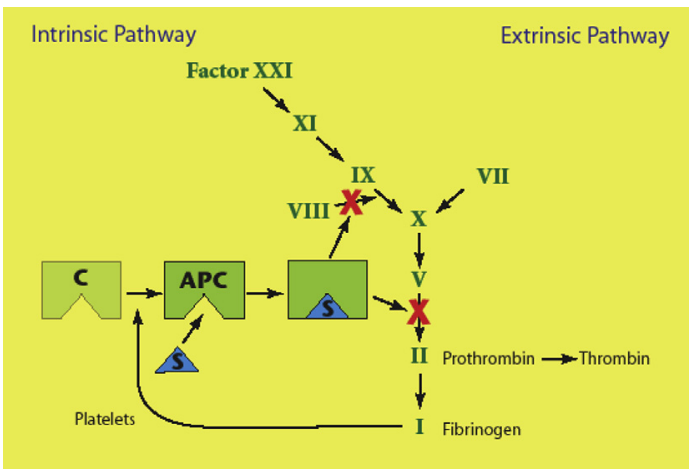

Fig. 2. The simplified coagulation cascade. Activated protein $C$ (APC) exerts an anticoagulant effect primarily through inhibition of factor $\mathrm{V}$. Protein $\mathrm{S}$ is required for this interaction. C, protein C. (From Jensen JT, Burke AE, Barnhart KT, et al. Effects of switching from oral to transdermal or transvaginal contraception on markers of thrombosis. Contraception 2008;78(6):451-8; with permission.)

active metabolites. These effects explain why EE increases clot risk even with transdermal or vaginal administration. 22,23

Because many studies have shown trends toward higher levels of thrombogenic factors and suppression of thrombolytic factors in third-generation progestins compared with second-generation pills, ${ }^{18-20}$ many experts think that the androgenic properties of a progestogen modify the estrogen effect on clotting factors. One important mediator measured in several studies is activated protein $C$ (APC) resistance; this seems to be increased with use of third-generation compared with second-generation progestogens. APC results from the binding of protein $S$ to protein $C$. Estrogens decrease levels of both of these anticoagulant factors. ${ }^{24}$ APC acts as an anticoagulant because it terminates the clotting cascade by cleaving activated factor $\mathrm{V}$ and VIII. ${ }^{18,20}$ Because APC resistance is the mechanism through which factor $V$ Leiden mutants become hypercoagulable, there is a temptation to equate biological plausibility with true risk. However, APC resistance has never been prospectively validated as a surrogate marker for VTE. ${ }^{25}$

Other studies have proposed the use of sex hormone-binding globulin (SHBG) as a surrogate marker of clot risk. ${ }^{26}$ SHBG, much like thyroid-binding globulin, is a large glycoprotein that is involved in sex hormone transport in the circulation. SHBG secretion seems to be hormonally regulated. Estrogen levels in pregnancy increase SHBG levels almost 10 -fold and oral estrogens or EE by any route also result in dosedependent increases. Similar to APC resistance, the increase in SHBG level is lower with androgenic progestogens like LNG than with less androgenic molecules like desogestrel or DRSP. However, like APC resistance, the suggestion that SHBG can serve as marker for relative estrogenicity, and in turn VTE risk, has never been validated. To date, no surrogate marker for VTE risk has been identified. ${ }^{25}$

\section{BACKGROUND RISKS}

Much of the criticism of early epidemiologic studies linking newer progestins to an increase in VTE risk has been a failure to address for 1 or more of the many risk factors that affect clot formation. How a study accounts and adjusts for confounding variables affect the association of progestogen type and VTE risk. Because no randomized trials exist to evaluate the differential effects of progestogens in $\mathrm{CHC}$, evaluation of the 
validity of study outcomes requires a careful assessment of potential baseline confounders and the evaluation of the VTE diagnosis.

\section{Confounding Factors}

Unrecognized differences in the baseline characteristics of study groups threaten the validity of conclusions reached in any study design. Several important demographic characteristics are known risk factors for VTE. First, VTE risk increases with age; incidence estimates vary from 0.7 per 10,000 woman-years in individuals 15 to 19 years old to 5.8 per 10,000 woman-years in individuals 45 to 49 years old. ${ }^{27}$ Another important risk factor is obesity. Obese women carry a 2-fold to 3-fold increased risk of VTE compared with women of normal weight. ${ }^{28-30}$ Because rates of obesity have rapidly increased over the last 2 decades, this creates a confounding cohort effect, because the population of women enrolled in recent studies will have higher VTE rates independent of progestogen type compared with cohorts enrolled in studies 20 years ago. Related to obesity, some recent studies have suggested that polycystic ovary syndrome (PCOS) may be an independent risk factor for VTE. ${ }^{31,32}$ Because managing symptoms of hyperandrogenism is a major therapeutic goal of PCOS treatment, providers may preferentially prescribe low-androgen pills to these high-risk women.

Other important VTE risks include smoking, malignancy, activity, and genetics. Hereditable factors are present in more than $25 \%$ of first-time VTE. ${ }^{4,6,27}$ The factor V Leiden mutation accounts for $30 \%$ of the DVTs in the United States and its mutations are present in white people (5.3\%) at a rate more than 10 times greater than in Asian people $(0.5 \%) .{ }^{19,33}$ The interaction of factor $V$ Leiden and other coagulopathies such as protein $\mathrm{C}$ or $\mathrm{S}$ deficiencies and $\mathrm{CHC}$ use is multiplicative; the risk of clot is increased 100 -fold in factor $\mathrm{V}$ Leiden homozygotes using $\mathrm{CHC} .{ }^{34}$ The high prevalence of factor $\mathrm{V}$ Leiden in the white population is an important factor to keep in mind because many of the large-scale database studies are conducted in Europe.

Another effect to note is the detection bias present when VTE rates from newer studies are compared with older ones. The availability of higher quality, noninvasive technologies like Doppler ultrasonography and computed tomography angiography has greatly improved the ability to see small clots. Whether or not these are clinically relevant, the increased use of these modalities in individuals perceived to be at high risk or in more recent studies may lead to bias. ${ }^{35}$

\section{Risk of Venous Thromboembolism Associated with Starting or Switching a Combined Method}

Multiple studies show that the risk of VTE is higher in new users. ${ }^{36-38}$ The increased risk associated with a new prescription is independent of other known risk factors such as age and body mass index (BMI), and is estimated to be 3 times higher in the first few months of use compared with after the first year. ${ }^{36}$ There are conflicting explanations for these phenomena. One widely accepted explanation is that continuing users make up a cohort of survivors, or women who are inherently, but perhaps intangibly, at lower risk. With the introduction of any new drug, users who are prone to adverse outcomes experience those conditions when they first begin use. $^{30,39}$ In the case of VTE, this may include women with nonclassic coagulopathies that are not picked up on screens for common mutations such as factor $V$ Leiden. This attrition of the susceptible is reflected in new cohorts because incoming women have unknown and untested backgrounds. However, existing cohorts are made of women who have survived and are therefore healthier users, which produces a differential selection bias that could account for some of the association seen with new pills and VTE. 
One biological explanation for the new-user effect is that, when initiating COC use, there is an equilibrating period when the body adjusts to the new state of hormoneinduced changes in coagulation. Support for this explanation comes from studies that suggest that women who have used COCs and then discontinue reassume an increased risk when they reinitiate the same pill. ${ }^{40}$ However, this comparison is further confounded by time, because age and changes in health status are different and therefore baseline risk may not be the same from one episode of usage to another.

Similar to new users, pill switchers are at higher risk of clot compared with continuing users, and this effect is true whether the change is from a secondgeneration to a third-generation or a third-generation to a second-generation pill. ${ }^{40}$ It is possible that new combinations lead to subtle changes in the balance of procoagulation and anticoagulation factors in the liver. Changes in coagulation markers have been identified in women switching from the pill to the transdermal patch or vaginal ring. ${ }^{41}$ Although the exact mechanism of this effect has not been elucidated, for women who develop additional risk factors, such as advancing age, weight, or inactivity, such a switch in the balance of coagulation factors may represent a destabilizing factor leading to clot formation.

\section{Prescribing Effect}

Preferential prescribing of new $\mathrm{CHC}$ formulations to high-risk women cannot be ruled out as the explanation for the differential VTE risks seen between progestogen type in case-control and database studies. Newer progestogens were developed and marketed with claims of decreased androgenicity to address complaints of androgenrelated side effects. Because these low-androgen progestogens also lead to an increase in high-density lipoprotein cholesterol, this likely led to preferential prescription to women at risk of cardiovascular disease. A survey of German physicians showed an increased likelihood to prescribe a third-generation pill to high-risk patients and also to refer women using third-generation pills for diagnostic work-up for DVT even if symptoms were mild or nonspecific. ${ }^{42}$ A Dutch study found that women using other cardiovascular medications were more likely to have been prescribed thirdgeneration than second-generation pills. ${ }^{43}$ A large prospective European cohort study showed preferential prescription of DRSP products in obese women and in women with preexisting arrhythmia, which is another risk factor for clot formation. ${ }^{37}$

The inverse dose response for estrogen identified by Farmer and Lawrenson ${ }^{44}$ provides additional convincing evidence for preferential prescription bias (Table 2). In contrast with an expected reduction in VTE risk with decreasing dose of EE, a consistent effect of increased risk with $20-\mu \mathrm{g}$ (introduced later) compared with $30-\mu \mathrm{g}$ pills was identified in the World Health Organization (WHO), Transnational, and UK General Practitioner's Database studies. ${ }^{45}$ This biologically implausible effect suggests preferential prescription of newer pills to high-risk women.

It is important to put in context the contraceptive choices available to women in the 1980s and 90s. Intrauterine device and implant use was uncommon, making the pill the most recommended contraceptive option, even in women with relative cardiovascular risk factors. It is not surprising that providers responded positively to the introduction of new COC formulations with beneficial effects on lipids.

\section{THIRD-GENERATION AND FOURTH-GENERATION PROGESTINS: HISTORY OF THE CONTROVERSY}

Whether VTE rates in users of third-generation and fourth-generation CHCs are increased in relation to second-generation pills remains highly controversial. Because 


\begin{tabular}{|c|c|c|c|c|c|c|c|}
\hline Study & Reference & Patients ( $n$ ) & OR & $95 \% \mathrm{Cl}$ & Patients ( $n$ ) & OR & $95 \% \mathrm{Cl}$ \\
\hline$=$ & & \multicolumn{3}{|c|}{ Desogestrel $+20 \mu \mathrm{g} \mathrm{EE}$} & \multicolumn{3}{|c|}{ Desogestrel $+30 \mu \mathrm{g} \mathrm{EE}$} \\
\hline WHO & Nonusers & 8 & 38.2 & $4.5-325$ & 27 & 7.6 & $3.9-14.7$ \\
\hline Transnational & LNG & 13 & 2.8 & $1.3-6.5$ & 32 & 1.5 & $0.9-2.5$ \\
\hline BCDSP (Jick) & LNG & 4 & 2.7 & NA & 26 & 1.9 & NA \\
\hline MediPlus UK & LNG & 13 & 2.9 & $0.9-10.0$ & 19 & 0.6 & $0.3-1.5$ \\
\hline$=$ & & \multicolumn{3}{|c|}{ Cyproterone $+35 \mu \mathrm{g} \mathrm{EE}$} & \multicolumn{3}{|c|}{ Cyproterone $+50 \mu \mathrm{g} \mathrm{EE}$} \\
\hline WHO & LNG & 9 & 5.1 & $1.3-20.3$ & 9 & 1.3 & $0.5-3.8$ \\
\hline
\end{tabular}

Abbreviations: $\mathrm{Cl}$, confidence interval; OR, odds ratio; WHO, World Health Organization.

From Farmer RDT, Lawrenson RA. Oral contraceptives and venous thromboembolic disease: the findings from database studies in the United Kingdom and Germany. Am J Obstet Gynecol 1998;179(3 Suppl):s78-86; with permission. 
VTE is an uncommon to rare event, a randomized controlled trial is not practical. Although case-control and database studies have found a consistent 2-fold increase in risk with third-generation and fourth-generation progestogens compared with LNG, this same effect has not been observed in large prospective cohort studies.

\section{The First Pill Scare}

Third-generation progestogens became available in COC formulations in the 1980s and rapidly gained widespread use. By the mid-1990s several observational studies suggested an increased risk of thrombosis with these pills. ${ }^{11-14}$ The WHO casecontrol study found an increased risk of VTE with desogestrel (odds ratio [OR], 2.4; 95\% confidence interval $[\mathrm{Cl}], 1.4-4.6)$ and gestodene (OR, 3.1; 95\% Cl, 1.6-5.9) compared with LNG. ${ }^{11}$ The transnational case-control study, conducted concurrently with the WHO, similarly found an increased OR of $1.5(95 \% \mathrm{Cl}, 1.1-2.1)$ in comparisons of third-generation with second-generation pills. ${ }^{14}$

Around the same time as these case-control studies, several large database cohort studies were also done. Database studies use national identifier numbers to link health records to prescriptions, allowing researchers to perform a retrospective cohort analysis linking exposures to outcomes. Although these types of studies allow researchers to calculate incidence rates and relative risk $(R R)$ for rare events, the retrospective nature limits the assessment of baseline confounding variables. Two prominent examples of these studies came out of the United Kingdom with conflicting results. The first, from Jick and colleagues, ${ }^{12}$ examining the General Practitioner's Research Database, found increased RRs with gestodene (RR, 1.8; 95\% Cl, 1.0-3.2) and desogestrel (RR, 1.9; $95 \% \mathrm{Cl}, 1.1-3.2)$ compared with LNG. Meanwhile, Farmer and colleagues ${ }^{46}$ probed a similar but nonoverlapping UK database of general practices (MediPlus) and performed similar cohort and nested case-control studies. Although the initial analysis showed an increased risk with third-generation pills, subanalysis showed that age was a significant confounder. Moreover, case-control analysis done in a similar way to the Jick and colleagues ${ }^{12}$ and $\mathrm{WHO}$ studies led to null results when comparing gestodene and desogestrel with LNG (OR, 0.87; 95\% Cl, 0.4-1.8; and OR, 0.84; 95\% Cl, 0.4-1.9 respectively).

\section{The Second Pill Scare}

Approximately a decade later, a second wave of epidemiologic studies reignited the debate about progestogen modification of VTE risk. Results from Lidegaard and colleagues, ${ }^{15}$ using the Danish National Database, confirmed the findings of the first pill scare showing an increased RR of VTE with desogestrel (RR, 1.82; 95\% Cl, 1.49-2.22) and gestodene (RR, 1.86; 95\% Cl, 1.59, 2.18), and found new associations with DRSP $(\mathrm{RR}, 1.64 ; 95 \% \mathrm{Cl}, 1.27-2.1)$ and cyproterone acetate (RR, 1.88; 95\% Cl, 1.47-2.42). These results were corroborated by several large case-controls studies from the United States, United Kingdom, and the Netherlands. Jick and colleagues, ${ }^{47}$ using a US insurance claims database, found a 2-fold increase in risk for VTE among users of DRSP products (OR, 2.3; 95\% Cl, 1.6-3.2). A similar increase in risk for DRSP was identified in the UK General Practice Research Database (OR, 2.7; 95\% Cl, 1.5-4.7). ${ }^{48}$ Most dramatically, a Dutch case-control study found a 6.3-fold increase in risk for DRSP compared with LNG (95\% Cl, 2.9-13.7). ${ }^{49}$ A study performed using a health claims database from the United States came to similar conclusions. ${ }^{50}$

However, consistency of effect seen in these results may reflect problems inherent in the shared methodology of these studies more than a true biological association, because confounding and bias could account for the observed differences. For example, the 2009 Lidegaard and colleagues ${ }^{15}$ study likely underestimated the rate 
of VTE in the LNG arm because the follow-up period started well after the introduction VTE in women using the DRSP pills.

\section{Contraceptive Ring and Patch}

Nonoral forms of $\mathrm{CHC}$ have also the subjects of controversy and debate. There have been concerns that the transdermal patch of $0.75 \mathrm{mg}$ of $E E$ and $6 \mathrm{mg}$ of norelgestromin (activate metabolite of norgestimate, a third-generation progestin) confers an increased risk for clot given higher sustained exposure to estrogen, despite lower peak levels. ${ }^{51}$ Similar to the research seen in the pill controversies, observational data regarding its safety are conflicting. Jick and colleagues ${ }^{52-54}$ published several nested case-control studies showing no increased risk for VTE or ATE using data from an insurance claim database compared with pills containing norgestimate or levonorgestrel. Another group using claims data from a single carrier found a 2-fold increase in VTE risk (OR, 2.0; 95\% Cl, 1.2-3.3) with no increased risk for ATE-related morbidity. ${ }^{5,56}$ Database cohort studies from Lidegaard and colleagues ${ }^{57}$ and the US Food and Drug Administration (FDA ${ }^{58}$ corroborated these findings. Moreover, measurements of hemostatic variables suggest changes favoring clot formation in patch users compared with $\mathrm{COC}$ users. ${ }^{59,60}$ However, no prospective studies adequate to evaluate the risk of VTE in patch users have been performed to date.

The vaginal ring releases $15 \mu \mathrm{g}$ of EE and $120 \mu \mathrm{g}$ of etonogestrel daily. Few studies are available regarding the vaginal ring. Lidegaard and colleagues ${ }^{57}$ used the Danish registries to evaluate clot risk in women using nonoral hormonal methods and found an increase (RR, 1.9; 95\% Cl, 1.3-2.7) in vaginal ring compared with LNG pill users. However, information on confounders such as smoking, family history, BMI, and thrombophilias were not reported in this study. In 2011, in response to the controversy raised by the Danish database studies, the FDA conducted a retrospective cohort study using data from 4 geographically diverse health plans that included 835,826 women with 898,251 person-years of $\mathrm{CHC}$ use to evaluate the risk of thrombotic and thromboembolic events and all-cause and cardiovascular mortality for 3 newer preparations (DRSP/EE pill, norelgestromin/EE patch, and the etonogestrel/EE ring). The main result of this study was a significantly higher risk of VTE in users of the patch (RR 1.55, 1.17, 2.07) and ring (RR 1.56, 1.02, 2.37) compared with low-dose pill comparators. However, because this study relied on insurance database records, no information was available on baseline confounders. ${ }^{58}$

\section{Prospective Studies}

True prospective research that identify baseline confounders and follow outcomes are generally considered to provide higher quality evidence that is less prone to bias than case-control or retrospective database studies ${ }^{61}$ To evaluate rare adverse events like VTE, large studies are required, and the expense and complexity make this type of research less common. Several important prospective studies of VTE risk have been completed in response to phase IV safety monitoring required as a condition of regulatory approval for several contraceptive products. The most important data concerning the cardiovascular safety of oral contraceptive pills come from 2 large cohort trials conducted by Dinger and colleagues. ${ }^{38}$ The European Active Surveillance (EURAS) study enrolled 58,674 European women initiating a new prescription for combined oral contraception, and contacted subjects every 6 months to assess safety outcomes. The prospective design allowed for collection of important risk factors for VTE such as BMI. Dinger and colleagues ${ }^{38}$ also excluded long-time users and focused on differentiating starters from switchers. Subjects contributed 142,475 
woman-years of follow-up, and loss-to-follow-up rates were impressively low (2.4\%). This study reflected real-world prescribing habits; providers could prescribe any pill to their patients, because there were no prescribed exclusionary criteria. Although this study did not specifically evaluate COCs by generation, no difference was found between DRSP and LNG (hazard ratio [HR], 1.0; 95\% Cl, 0.6-1.8) and DRSP with other oral contraceptives (HR, 0.8; $95 \% \mathrm{Cl}, 0.5-1.3)$. The subsequent International Surveillance Study of Women Taking Oral Contraceptives (INAS-OC) followed more than 85,000 women in the United States and 6 European nations for safety outcomes, including VTE, in users of $20 \mu \mathrm{g}$ EE/3 mg DRSP on a 24/4 regimen (24 days of pills Q10 with hormones followed by 4 days of hormone-free pills). Again, this had an impressively low lost-to-follow-up rate (3.3\%) and the prospective design allowed capture of confounding baseline characteristics. Similar to EURAS, there was no increased risk of VTE seen in DRSP users compared with LNG users (HR, 0.8; 95\% Cl, 0.4-1.3).

In addition, a large prospective study has evaluated the etonogestrel vaginal contraceptive ring. ${ }^{62-64}$ Dinger and colleagues, ${ }^{62}$ using essentially the same methodology as in the EURAS and INAS-OC studies, followed 33,295 subjects for a total of 66,489 woman-years. Dinger and colleagues ${ }^{62}$ showed no difference in the risk for VTE and ATE including an HR of $0.8(95 \% \mathrm{Cl}, 0.5-1.6)$ for VTE in ring users compared with pill users. Although all 3 of these studies were criticized for being industry funded, regulatory authorities mandated them and their protocols and analyses were reviewed and approved by independent advisory boards.

\section{SUMMARY}

Hormonal contraception remains one of the most important contributions to women's health in the last century. The birth control pill has dramatically changed the medical, social, economic, and political fates of women around the world by reducing unintended pregnancy and childbirth. Commitment to improving these drugs and ensuring their safety strengthens the benefits women derive from contraception.

The well recognized dose-dependent effects of estrogen on coagulation are undeniable. However, the comparison of those effects with the much higher physiologic levels of estrogen seen in pregnancy is important because women take oral contraceptive pills primarily to prevent pregnancy. The risk of VTE in pregnancy and the immediate postpartum period is approximately 10 to 100 times higher than with COC use. ${ }^{45}$ Women who experience adverse cardiovascular events on COCs would also be at high risk for those events in pregnancy. There is no convincing evidence that, by avoiding $\mathrm{CHCs}$, women who wish to get pregnant one day reduce their risk of a serious thrombotic event. Moreover, beyond the discussion of the increased risk for VTE, women who report ever having used a COC have lower all-cause mortalities than never-users. ${ }^{14}$

The progestogen modification of this risk remains controversial. Biologically plausible mechanisms and proposed surrogate markers have not been proved. Meanwhile, the epidemiologic literature is nuanced and susceptible to bias. The ease with which slight changes in methodology can alter findings reflects the small differences that are being debated and the inherent difficulty in adjusting retrospective data. At this time, the best prospective literature does not show an increased risk with use of third-generation or fourth-generation progestogens in COCs, or with the etonogestrel ring. Moreover, these data remain available for reanalysis and reappraisal.

However, the argument that the consequences of VTE are dire should not be overlooked. VTE is often a fatal event and the significance of even 1 preventable death of a young woman cannot be dismissed. Some countries, like France, have adopted a conservative approach that an LNG product should always be used for the initial 
COC prescription, followed by a switch only if intolerance develops. Because these pills are also generally available at low cost, a medical economic argument can also be made for first-line prescription of LNG pills. Whether or not the safest alternative should be the default also rests on a growing but still inadequate body of literature describing the differential benefits of different progestins. Convincing literature supporting the superiority of the newer progestogens is also lacking. However, more subtle aspects of possible tolerability may emerge in the clinician-patient consultation, so policies that restrict the prescribing privileges of clinicians should be carefully reviewed and evidence based.

Ultimately, it is the individual provider's obligation to prescribe whichever contraceptive is deemed most beneficial for the individual patient. To that end, it is important to assess women who have baseline increased risks for thrombosis. Women who have risk factors such as a personal or significant family history for VTE or a concomitant medical disease should not receive a combined product. The WHO and US Centers for Disease Control and Prevention Medical Eligibility Criteria for Contraceptive Use should be consulted to determine the best contraception for women with medical comorbidities. ${ }^{65,66}$ For most women without baseline risk factors, the use of a combined method is safe. Clinicians should present a discussion of potential risks and benefits of existing and new products to allow women to make informed choices.

\section{DISCLOSURE OF INTEREST}

L. Han states no conflict of interest and has received no payment in the preparation of this article. J.T. Jensen has received payments for consulting from Agile Pharmaceu- Q12 ticals, Abbvie Pharmaceuticals, Bayer Healthcare, ContraMed, Evofem Inc, HRA Pharma, Merck Pharmaceuticals, Teva Pharmaceuticals, and the Population Council. $\mathrm{He}$ has also received research funding from Abbvie, Bayer, the Population Council, the National Institute of Health, and the Bill and Melinda Gates Foundation. These companies and organizations may have a commercial or financial interest in the results of this research and technology. These potential conflicts of interest have been reviewed and managed by the Oregon Health \& Science University.

\section{REFERENCES}

1. Mosher WD, Jones J. Use of contraception in the United States: 1982-2008. Vital Health Stat 23 2010;(29):1-44.

2. White $\mathrm{RH}$. The epidemiology of venous thromboembolism. Circulation 2003; 107(23 Suppl 1):14-8.

3. Heit JA. The epidemiology of venous thromboembolism in the community. Arterioscler Thromb Vasc Biol 2008;28(3):370-2.

4. Beckman MG, Hooper WC, Critchley SE, et al. Venous thromboembolism. Am J Prev Med 2010;38(4):S495-501.

5. Kahn SR, Ducruet T, Lamping DL, et al. Prospective evaluation of health-related quality of life in patients with deep venous thrombosis. Arch Intern Med 2005; 165(10):1173-8.

6. Heinemann LAJ, Dinger JC. Range of published estimates of venous thromboembolism incidence in young women. Contraception 2007;75(5):328-36.

7. Lidegaard $\varnothing$, Løkkegaard E, Jensen A, et al. Thrombotic stroke and myocardial infarction with hormonal contraception. N Engl J Med 2012;366(24):2257-66.

8. Ischaemic stroke and combined oral contraceptives: results of an international, multicentre, case-control study. WHO Collaborative Study of Cardiovascular Disease and Steroid Hormone Contraception. Lancet 1996;348(9026):498-505. 
9. Margolis KL, Adami H-O, Luo J, et al. A prospective study of oral contraceptive use and risk of myocardial infarction among Swedish women. Fertil Steril 2007; 88(2):310-6.

10. Bitzer J, Amy J-J, Beerthuizen R, et al. Statement on combined hormonal contraceptives containing third- or fourth-generation progestogens or cyproterone acetate, and the associated risk of thromboembolism. J Fam Plann Reprod Health Care 2013;39(3):156-9.

11. Venous thromboembolic disease and combined oral contraceptives: results of international multicentre case-control study. World Health Organization Collaborative Study of Cardiovascular Disease and Steroid Hormone Contraception. Lancet 1995;346(8990):1575-82.

12. Jick H, Jick SS, Gurewich V, et al. Risk of idiopathic cardiovascular death and nonfatal venous thromboembolism in women using oral contraceptives with differing progestagen components. Lancet 1995;346(8990):1589-93.

13. Bloemenkamp KWM, Helmerhorst FM, Rosendaal FR, et al. Enhancement by factor $\checkmark$ Leiden mutation of risk of deep-vein thrombosis associated with oral contraceptives containing a third-generation progestagen. Lancet 1995;346(8990):1593-6.

14. Spitzer WO, Lewis MA, Heinemann LA, et al. Third generation oral contraceptives and risk of venous thromboembolic disorders: an international case-control study. Transnational Research Group on Oral Contraceptives and the Health of Young Women. BMJ 1996;312(7023):83-8.

15. Lidegaard O, Lokkegaard E, Svendsen AL, et al. Hormonal contraception and risk of venous thromboembolism: national follow-up study. BMJ 2009; 339(aug13 2):b2890.

16. Stanczyk FZ. All progestins are not created equal. Steroids 2003;68(10-13): 879-90.

17. Stanczyk FZ, Hapgood JP, Winer S, et al. Progestogens used in postmenopausal hormone therapy: differences in their pharmacological properties, intracellular actions, and clinical effects. Endocr Rev 2013;34(2):171-208.

18. Oral Contraceptive and Hemostasis Study Group. The effects of seven monophasic oral contraceptive regimens on hemostatic variables: conclusions from a large randomized multicenter study. Contraception 2003;67(3):173-85.

19. Vandenbroucke JP, Koster T, Rosendaal FR, et al. Increased risk of venous thrombosis in oral-contraceptive users who are carriers of factor $\mathrm{V}$ Leiden mutation. Lancet 1994;344(8935):1453-7.

20. Kemmeren JM, Algra A, Meijers JCM, et al. Effect of second- and third-generation oral contraceptives on the protein $C$ system in the absence or presence of the factor V Leiden mutation: a randomized trial. Blood 2004;103(3):927-33.

21. Mantha S, Karp R, Raghavan V, et al. Assessing the risk of venous thromboembolic events in women taking progestin-only contraception: a meta-analysis. BMJ 2012;345(aug07 2):e4944.

22. Ansbacher R. The pharmacokinetics and efficacy of different estrogens are not equivalent. Am J Obstet Gynecol 2001;184(3):255-63.

23. Canonico M, Oger E, Plu-Bureau G, et al. Hormone therapy and venous thromboembolism among postmenopausal women: impact of the route of estrogen administration and progestogens: the ESTHER Study. Circulation 2007;115(7):840-5.

24. Tchaikovski SN, Rosing J. Mechanisms of estrogen-induced venous thromboembolism. Thromb Res 2010;126(1):5-11.

25. Stanczyk FZ, Grimes DA. Sex hormone-binding globulin: not a surrogate marker for venous thromboembolism in women using oral contraceptives. Contraception 2008;78(3):201-3. 
661

662

663

664

665

666

667

668

669

670

671

672

673

674

675

676

677

678

679

680

681

682

683

684

685

686

687

688

689

690

691

692

693

694

695

696

697

698

699

700

701

702

703

704

705

706

707

708

709

710

711

26. Odlind V, Milsom I, Persson I, et al. Can changes in sex hormone binding globulin predict the risk of venous thromboembolism with combined oral contraceptive pills? Acta Obstet Gynecol Scand 2002;81(6):482-90.

27. Lidegaard $\varnothing$, Milsom I, Geirsson RT, et al. Hormonal contraception and venous thromboembolism. Acta Obstet Gynecol Scand 2012;91(7):769-78.

28. Edelman A, Jensen J. Obesity and hormonal contraception: safety and efficacy. Semin Reprod Med 2012;30(06):479-85.

29. Edelman A. Contraceptive considerations in obese women. Contraception 2009; 80(6):583-90.

30. Shapiro S, Dinger J. Risk of venous thromboembolism among users of oral contraceptives: a review of two recently published studies. J Fam Plann Reprod Health Care 2010;36(1):33-8.

31. Okoroh EM, Hooper WC, Atrash HK, et al. Is polycystic ovary syndrome another risk factor for venous thromboembolism? United States, 2003-2008. Am J Obstet Gynecol 2012;207(5):377.e1-8.

32. Bird ST, Hartzema AG, Brophy JM, et al. Risk of venous thromboembolism in women with polycystic ovary syndrome: a population-based matched cohort analysis. Can Med Assoc J 2013;185(2):E115-20.

33. Bloemenkamp KWM, Helmerhorst FM, Rosendaal FR, et al. Thrombophilias and gynaecology. Best Pract Res Clin Obstet Gynaecol 2003;17(3):509-28.

34. Hatcher RA, Trussell J, Nelson AL. Contraceptive technology. Ardent Media; 2008.

35. Wells $P$, Anderson D. The diagnosis and treatment of venous thromboembolism. Hematology Am Soc Hematol Educ Program 2013;2013(1):457-63.

36. Suissa S, Blais L, Spitzer WO, et al. First-time use of newer oral contraceptives and the risk of venous thromboembolism. Contraception 1997;56(3):141-6.

37. Dinger JC, Heinemann LAJ, Kühl-Habich D. The safety of a drospirenonecontaining oral contraceptive: final results from the European Active Surveillance Study on Oral Contraceptives based on 142,475 women-years of observation. Contraception 2007;75(5):344-54.

38. Dinger J, Bardenheuer K, Heinemann K. Cardiovascular and general safety of a 24-day regimen of drospirenone-containing combined oral contraceptives: final results from the International Active Surveillance Study of Women Taking Oral Contraceptives. Contraception 2014;89(4):253-63.

39. Speroff L, Darney PD. A clinical guide for contraception. Lippincott Williams \& Wilkins; 2010.

40. Suissa S, Spitzer WO, Rainville B, et al. Recurrent use of newer oral contraceptives and the risk of venous thromboembolism. Hum Reprod 2000;15(4): 817-21.

41. Jensen JT, Burke AE, Barnhart KT, et al. Effects of switching from oral to transdermal or transvaginal contraception on markers of thrombosis. Contraception 2008;78(6):451-8.

42. Heinemann LAJ, Lewis MA, Assmann A, et al. Could preferential prescribing and referral behaviour of physicians explain the elevated thrombosis risk found to be associated with third generation oral contraceptives? Pharmacoepidemiol Drug Saf 1996;5(5):285-94.

43. Herings $\mathrm{R}$, Urquhart J, Leufkens $\mathrm{H}$. Venous thromboembolism among new users of different oral contraceptives. Lancet 1999;354(9173):127-8.

44. Farmer RDT, Lawrenson RA. Oral contraceptives and venous thromboembolic disease: the findings from database studies in the United Kingdom and Germany. Am J Obstet Gynecol 1998;179(3 Supplement):s78-86. 
45. Lewis MA, Heinemann LAJ, MacRae KD, et al. The increased risk of venous thromboembolism and the use of third generation progestagens: role of bias in observational research. Contraception 1996;54(1):5-13.

46. Farmer R, Lawrenson R, Thompson $\mathrm{C}$, et al. Population-based study of risk of venous thromboembolism associated with various oral contraceptives. Lancet 1997;349(9045):83-8.

47. Jick SS, Hernandez RK. Risk of non-fatal venous thromboembolism in women using oral contraceptives containing drospirenone compared with women using oral contraceptives containing levonorgestrel: case-control study using United States claims data. BMJ 2011;342(apr21 2):d2151.

48. Parkin L, Sharples K, Hernandez RK, et al. Risk of venous thromboembolism in users of oral contraceptives containing drospirenone or levonorgestrel: nested case-control study based on UK General Practice Research Database. BMJ 2011;342(apr21 2):d2139.

49. Van Hylckama Vlieg A, Helmerhorst FM, Vandenbroucke JP, et al. The venous thrombotic risk of oral contraceptives, effects of oestrogen dose and progestogen type: results of the MEGA case-control study. BMJ 2009;339(aug13 2): b2921.

50. Research C for DE and. Drug Safety and Availability - FDA drug safety communication: Updated information about the risk of blood clots in women taking birth control pills containing drospirenone. Available at: http://www.fda.gov/Drugs/ DrugSafety/ucm299305.htm. Accessed March 3, 2015.

51. Van den Heuvel MW, van Bragt AJM, Alnabawy AKM, et al. Comparison of ethinylestradiol pharmacokinetics in three hormonal contraceptive formulations: the vaginal ring, the transdermal patch and an oral contraceptive. Contraception 2005;72(3):168-74.

52. Jick S, Kaye JA, Li L, et al. Further results on the risk of nonfatal venous thromboembolism in users of the contraceptive transdermal patch compared to users of oral contraceptives containing norgestimate and $35 \mu \mathrm{g}$ of ethinyl estradiol. Contraception 2007;76(1):4-7.

53. Jick SS, Hagberg KW, Hernandez RK, et al. Postmarketing study of ORTHO EVRA ${ }^{\circledR}$ and levonorgestrel oral contraceptives containing hormonal contraceptives with $30 \mathrm{mcg}$ of ethinyl estradiol in relation to nonfatal venous thromboembolism. Contraception 2010;81(1):16-21.

54. Jick SS, Kaye JA, Russmann S, et al. Risk of nonfatal venous thromboembolism in women using a contraceptive transdermal patch and oral contraceptives containing norgestimate and $35 \mu \mathrm{g}$ of ethinyl estradiol. Contraception 2006; 73(3):223-8.

55. Dore DD, Norman H, Loughlin J, et al. Extended case-control study results on thromboembolic outcomes among transdermal contraceptive users. Contraception 2010;81(5):408-13.

56. Cole JA, Norman H, Doherty $M$, et al. Venous thromboembolism, myocardial infarction, and stroke among transdermal contraceptive system users. Obstet Gynecol 2007;109(2, Part 1):339-46.

57. Lidegaard $\varnothing$, Nielsen LH, Skovlund CW, et al. Venous thrombosis in users of nonoral hormonal contraception: follow-up study, Denmark 2001-10. BMJ 2012;344: e2990.

58. US Food and Drug Administration, Office of Surveillance and Epidemiology. Combined hormonal contraceptives (CHCs) and the risk of cardiovascular disease endpoints. Available at: www.fda.gov/downloads/Drugs/DrugSafety/UCM277384.pdf. Accessed May 21, 2015. 
59. Johnson JV, Lowell J, Badger GJ, et al. Effects of oral and transdermal hormonal contraception on vascular risk markers: a randomized controlled trial. Obstet Gynecol 2008;111(2 Pt 1):278-84.

60. White T, Ozel B, Jain JK, et al. Effects of transdermal and oral contraceptives on estrogen-sensitive hepatic proteins. Contraception 2006;74(4):293-6.

61. Schulz KF, Grimes DA. The Lancet handbook of essential concepts in clinical research. Elsevier; 2006.

62. Dinger J, Möhner S, Heinemann K. Cardiovascular risk associated with the use of an etonogestrel-containing vaginal ring. Obstet Gynecol 2013;122(4):800-8.

63. Reid RL, Westhoff C, Mansour D, et al. Oral Contraceptives and venous thromboembolism consensus opinion from an International Workshop held in Berlin, Germany in December 2009. J Fam Plann Reprod Health Care 2010;36(3):117-22.

64. Vessey M, Yeates D, Flynn S. Factors affecting mortality in a large cohort study with special reference to oral contraceptive use. Contraception 2010;82(3): 221-9.

65. WHO. Medical eligibility criteria for contraceptive use. WHO. Available at: http:// www.who.int/reproductivehealth/publications/family_planning/9789241563888/en/ . Accessed May 18, 2015.

66. CDC - United States medical eligibility criteria (USMEC) for contraceptive use reproductive health. Available at: http://www.cdc.gov/reproductivehealth/ unintendedpregnancy/usmec.htm. Accessed July 28, 2014. 